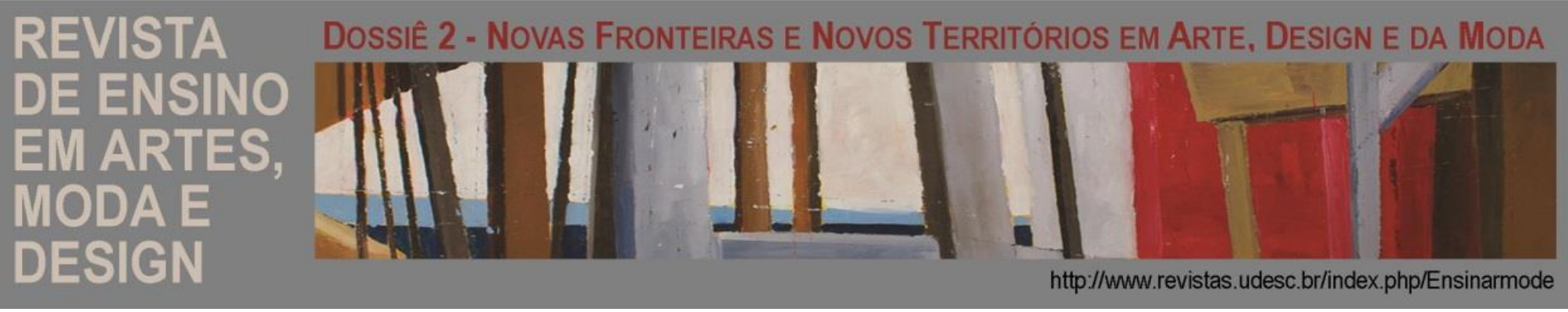

\title{
O ENSINO DE HISTÓRIA DA MODA NO SUL DO PAÍS
}

L'enseignement de l'histoire de la moda au sud du Brèsil

Mara Rúbia Sant'Anna'

\section{RESUMO}

Estudo exploratório a partir de dados coletados junto às instituições de ensino superior de Santa Catarina e Rio Grande do Sul, tendo como objetivo discutir a dimensão do ensino de história da moda nos cursos de Design de Moda, cotejando a importância do desenvolvimento da consciência histórica crítica dos estudantes e, para tanto, são analisadas as metodologias de ensino aplicadas e os objetivos gerais que as motivaram, conforme encontrados nos planos de ensino pesquisados, bem como ponderadas a formação e capacitação dos professores atuantes no ensino de história na época da pesquisa de campo. Os resultados indicam um caminho de reflexão a ser percorrido tanto por instituições de ensino como por parte dos professores e profissionais envolvidos no trabalho universitário.

Palavras-chave: Metodologias de ensino. Perfil do professor. Ensino superior. Design de Moda.

\begin{abstract}
Résumé
Étude exploratoire basée sur des données recueillies auprès des établissements d'enseignement supérieur de Santa Catarina et Rio Grande do Sul, visant à discuter la dimension de l'enseignement de l'histoire de la mode dans les cours de design de mode, comparant l'importance du développement de la conscience historique critique chez les étudiants et, à cette fin, les méthodologies pédagogiques appliquées et les objectifs généraux qui les ont motivés dans les plans d'enseignement recherchés sont analysés, ainsi que, la formation et la qualification des enseignants actifs dans l'enseignement de l'histoire dans la recherche de terrain. Les résultats indiquent une manière de réfléchir à suivre par les établissements d'enseignement et par les enseignants et les professionnels impliqués dans le travail universitaire.
\end{abstract}

Mot-clés: Méthodologies Pédagogiques. Profil de l'enseignant. Enseignement supérieur. Design de mode.

\footnotetext{
${ }_{1}^{1}$ Professora efetiva da Universidade do Estado de Santa Catarina. Doutora em História pela UFRGS (2005) e pós-doutoramento em 2011 pela Université de Strasbourg e em 2017 pela Universidade Federal do Rio de Janeiro/PPGAV.

E-mail: sant.anna.udesc@gmail.com | Lattes: http://lattes.cnpq.br/8949042412277782

Revista ENSINARMODE, Florianópolis, Vol. 2, N. 2, Junho-Setembro 2018, p. 170-199. DOI: http://dx.doi.org/10.5965/25944630222018170 | ISSN 2594-4630
} 


\section{DE ONDE PARTIMOS}

A Universidade foi constituída na era moderna como um espaço educativo que deveria ir muito além da transmissão e reprodução do conhecimento. Através de diferentes forças sociais e históricas, as instituições de ensino superior foram forjando seus alicerces e hoje se constroem como instrumento para a transformação da sociedade.

Silva e Reis (2011) apontam que a Universidade é local privilegiado, onde as ações desenvolvidas deveriam desafiar intelectualmente os estudantes, através de aulas instigantes, discussões, problematizações e buscas de soluções, visando a criar profissionais competentes, satisfeitos de forma plena e agentes de transformações sociais.

Para tanto, o professor universitário, além do domínio dos saberes e conteúdos, deve estar apto a desenvolver o olhar crítico e o pensamento reflexivo, colocando o estudante não apenas na posição de assimilador, mas de interpretador e questionador dos conteúdos apreendidos.

Logo, faz-se necessário que o professor universitário tenha habilidades e acesso às ferramentas de ensino que possibilitem esse trâmite de conhecimentos de maneira instigante e promotora de profissionais críticos e criativos. A metodologia, a bibliografia e avaliações, itens obrigatórios num plano de ensino, somente se tornam importantes instrumentos de ensino e aprendizagem, quando coerentes entre si e pautados na ementa definida para a disciplina. Assim, é imprescindível que o professor tenha conhecimentos de didática e pedagogia, independente do amplo domínio que possua em sua área de conhecimento, pois, apenas assim, estimulará o processo cognitivo dos estudantes (LEITE, 2016).

De acordo com Anastasiou (2002), a maioria dos professores, que atua em instituições de ensino superior, não teve, em seus cursos universitários, uma preparação para a docência, com exceção dos professores oriundos da área da Educação ou Licenciatura que, durante os anos universitários, discutiram questões teóricas e práticas relativas à questão do ensino e da aprendizagem.

Nas disciplinas de História da Moda, oferecidas nos cursos superiores de Design de Moda ou, simplesmente, Moda (BONADIO, MARINHO, 2016), a situação não é diferente. 
Portanto, este artigo tem como objetivo discutir a dimensão do ensino de história da moda nos cursos de Design de Moda, cotejando a importância do desenvolvimento da consciência história crítica dos estudantes. Para tanto, são ponderados dois aspectos: primeiramente, as metodologias de ensino aplicadas e os objetivos gerais que as motivaram e, por último, a formação e capacitação dos professores atuantes no ensino de história na época da pesquisa de campo, 2012 e 2013.

Tendo em pauta as questões amplas do ensino superior e de seu corpo docente (SADALLA, 2016) e o objetivo proposto acima, o artigo se desenvolve com as seguintes partes: introdutoriamente é discutido o papel do ensino de história a partir das discussões sobre a consciência histórica, como Cerri (2011) propõe subtítulo 2. $\mathrm{Na}$ sequência, reflexões são realizadas sobre a importância do planejamento e das metodologias do ensino. Os objetivos previstos nos planos de ensino também são confrontados às metodologias propostas, a fim de averiguar se entre eles havia coerência e possibilidade de eficácia no planejado - subtítulo 3 e seus itens. Completando a discussão, a formação e titulação dos profissionais responsáveis por essas disciplinas são analisadas e se reflete como isso pode impactar na sala de aula e na formação dos profissionais de moda, através do viés quantitativo - subtítulo 4.

Ao longo da argumentação, são demonstrados, graficamente, os dados coletados nos planos de ensino de história da moda, aplicados em IES dos estados de Santa Catarina e Rio Grande do Sul, no ano de 2012 e, circularmente, a formação dos professores, a condição de produção da consciência histórica crítica e o uso das metodologias de ensino se interpõem na argumentação em vista do objetivo geral.

\section{A IMPORTÂNCIA DA CONSCIÊNCIA HISTÓRICA CRÍTICA}

De acordo com Cerri (2011), a historicidade é condição de existência humana, nos constitui como espécie, variando apenas as formas de apreensão desse fenômeno, acima de tudo cotidiano e social. A partir do pensar histórico, atrelando os acontecimentos a uma linha de tempo, adquirimos consciência do passado e da possibilidade de construção do futuro, formando a compreensão do que de fato é a história: a sucessão do inesperado, criação constante, indo além de 
determinação e continuidade; ação dos sujeitos no tempo, por meio de suas experiências sociais, com toda a complexidade de sua dimensão coletiva, histórica e singular.

Talvez, para leigos, a história da moda não devesse ser cobrada de investimentos de criticidade como outros temários o são, tais como a história dos operários ou a história política. Ledo engano, as considerações que seguem tratam da história e sua escrita e, logo, qualquer tema que seja trabalhado pelo viés dessa área de conhecimento deve ser submetido aos mesmos preceitos teóricometodológicos.

No contexto de sociedades ocidentais, marcadas pelo Cristianismo, de herança clássica, originou-se a importância dada ao registro e à narração dos eventos. As coisas são analisadas pela sua antiguidade ou novidade, familiaridade ou estranheza. O tempo dos acontecimentos determina o grau de importância e intimidade que os fatos adquirem nessa narrativa, numa oposição entre o novo e velho, que pode enobrecer, reafirmar ou invalidar o narrado, dependendo do objeto dessa narração e a quem ela serve ideologicamente.

Assim, passado e futuro são sujeitos ativos do presente das sociedades. Os fatos históricos são relativos, dependem do ponto de vista das sociedades que os conservam na forma de uma memória social hegemônica, na maioria das vezes. O que se constitui na História, com letra maiúscula e repassada nos livros didáticos, se firma numa narrativa lógica e racional, quase sempre se fundindo no que se institui como identidade nacional e utilizando mitos fundadores das instituições que patrocinam a constituição de uma memória nacional ou coletiva, como o Estado, a própria História, as Religiões e a Escola.

Walter Benjamin, em suas conhecidas Teses para o conceito de História, em 1940, já havia alertado que "A verdadeira imagem do passado perpassa, veloz. O passado só se deixa fixar, como imagem que relampeja irreversivelmente, no momento em que é reconhecido" (Tese 5). Completando o alerta, Benjamin ainda afirma: "articular historicamente o passado não significa conhecê-lo 'como ele de fato foi'. Significa apropriar-se de uma reminiscência, tal como ela relampeja no momento de um perigo" (Tese 6) (BENJAMIN, 1987, p. 224).

Contudo, diferente da História, deve-se considerar que a consciência história é um fenômeno inerente à existência humana, resultante da potência da memória e da capacidade de transmissão do vivido. É uma forma de conhecer que 
se firma na tomada de consciência da temporalidade que nos cerca. Por meio da consciência histórica, são explicados os fenômenos gerais, intencionais, sociais etc. e, também, explicados os fenômenos não intencionais, nem subjetivos que são naturais e sofridos, como a morte, na medida em que se acoplam numa linha do tempo e, por um esforço humano e racional, causalidades são atribuídas entre o antes e o depois. A despeito dessa experiência de tempo comum aos humanos, o pensar historicamente vai mais além e agregar à consciência história a criticidade, o que implica não aceitar informações sem considerar o contexto de sua produção no tempo, o que também o humano tem capacidade de aprender a fazer, na medida em que comunica suas experiências sociais e abstrai de sua corporeidade a noção de tempo que o cerca como subjetividade social lúcida.

Segundo Antoine Proust (2008), a História:

Aparentemente, ela está empenhada perpetuamente em conciliar contradições: tem necessidade de fatos, extraídos de fontes; no entanto, sem serem questionados, os vestígios permanecem silenciosos e nem sequer são "fontes". Convém ser já historiador para conhecer as questões a serem formuladas às fontes, assim como os procedimentos suscetíveis de levá-las a exprimir-se. O método crítico, pelo qual é garantido o estabelecimento dos fatos, supõe, por si só, um saber histórico confirmado. (PROUST, 2008, p. 133)

O pensador francês, além de indicar a dialética como condição primeira da História, aponta que o historiador tem sua especificidade em operar com essa condição, a fim de produzir criticamente o conhecimento sobre o passado e, por isso, completa a frase acima dizendo: "Em suma, é necessário ser historiador para fazer história" (PROUST, 2008, p. 133).

Ainda, refletindo com Proust, pode-se alertar para a noção de tempo tão cara à história. Ele nos diz:

Por sua vez, o tempo, ou seja, a dimensão diacrônica constitutiva da questão no âmbito da história, não é um quadro vazio que seria preenchido por fatos, mas uma estrutura modelada pela sociedade e pela história já escrita. Servindo-se dele como um material, o historiador deve considerá-lo também como um verdadeiro ator de seu roteiro. (PROUST, 2008, p. 133)

Portanto, o objetivo da educação histórica não é formar a consciência histórica, presumindo que ela já existe no estudante, pois essa se desenvolve por meio da interação social desde o momento em que o sujeito compreende a noção do "ontem", do "antes", do "depois" e do "amanhã". Sobretudo, o objetivo da educação histórica é atribuir criticidade à consciência histórica. 
Mediar as contribuições da ciência histórica e as várias adequações da consciência histórica conforme os estudantes e comunidades em que se encaixam, possibilitando o pensamento crítico histórico, considerando a contextualização da produção tecnológica, cultural e discursiva, bem como as tensas relações sociais e de poder estabelecidas na produção do sistema de moda, é o papel do professor de história. Só assim seu trabalho garantirá que passado e presente se vinculem nas criações produzidas pelo futuro designer de moda e no posicionamento deste diante dos desafios sociais, culturais e econômicos que o mundo do trabalho the apresentará.

Outros pesquisadores, de diversas áreas, já se dedicaram a estudos que relacionam a importância do ensino da história para as mais diversas áreas de atuação e estudo. É o caso de Cabral (1999) que propôs reflexões acerca da história e da medicina, na tríade do passado, presente e futuro. A autora frisa que, além de a história responder a questões práticas que a ação médica requer, também se refere ao estudo direcionado às relações sociais de produção e poder que os homens estabelecem entre si e a natureza, concluindo que traçar a história do adoecer significa colocar um evento dentro de um contexto, relacionando-o como parte de um todo compreensível. Dessa maneira, Maria Helena Cabral, ao abordar o adoecimento como um processo que produz diferentes entendimentos sobre a doença e o doente, frisa a validade de uma investigação que una saberes médico e historiográfico, para a melhor capacitação dos futuros médicos, cujo principal objetivo deve ser tratar os doentes e não as doenças.

Outro exemplo é o trabalho realizado por Oki e Moradillo (2008), cujo objetivo foi de explorar as proximidades entre História e Filosofia da Ciência da Educação Científica, especificadamente, o ensino de História da Química. A investigação didática teve duas principais finalidades: identificar concepções prévias dos estudantes sobre aspectos da natureza da ciência e avaliá-las, com abordagem explícita de conteúdos da Filosofia da Ciência, em contextos históricos diversificados. Avaliando os resultados obtidos, Maria Conceição Oki e Edílson Moradillo concluíram que o referencial histórico-epistemológico, trabalhado pelos cursos pesquisados, contribuiu para que os estudantes de Química adquirissem uma imagem mais atual de ciência e melhor formação inicial. A disciplina História da Química criou um espaço importante para o conhecimento da natureza da ciência, 
para o aprendizado significativo de conceitos químicos por parte dos estudantes, segundo Oli e Moradillo.

Ferreira (2005) discute a importância da história no ensino da Matemática e utiliza em seus estudos os manuais dos professores. Nesses livros didáticos, encontram-se, geralmente, notas históricas, referências a importantes matemáticos, explicações sobre sua inventividade, o que e como fizeram. Porém, Terezinha Ferreira concluiu que esses materiais são pouco utilizados pelos professores: "muitos deles não conseguem fazer uso da História da Matemática em suas aulas". Segundo a autora, a própria história da Matemática deveria ser encarada como recurso didático que facilita a compreensão e desperta a motivação no estudante, "ajudando-o no entendimento de como as regras foram formuladas e assim entenda que tudo teve uma razão para existir" (FERREIRA, 2005, p. 138).

Todos os autores, de Ferreira a Cabral, apontam para um ponto comum, apesar das divergências entre os focos de pesquisa: a História é uma área de conhecimento importante, tornando-se um fator facilitador da compreensão do campo aplicado onde o aprendiz se encontra. Além disso, por dialogar com a própria condição histórica do sujeito, o estudante durante as aulas de História é motivado a se posicionar diante das teorias que lhe são apresentadas e mesmo diante das instruções práticas que cabem em sua profissão. Desta maneira, o aprendiz é estimulado ao entendimento das relações sociais de produção e poder que envolvem e culminam nas transformações/produções que ele terá a incumbência de fazer no exercício de sua profissão.

A História, o passado e o presente se vinculam aos projetos contemporâneos sociais, culturais e políticos para a projeção de um futuro em função da interpretação do passado, em qualquer área. A interpretação do passado deve ser promovida pelo professor de História, a fim de motivar uma postura criativa e crítica no ordenamento das rédeas históricas do mundo que nos cerca. $E$ por "criar", entende-se processo pelo qual os seres humanos concebem, formam, geram, desenvolvem e materializam ideias, transformando o seu derredor.

Cerri (2011) defende que passado e suas projeções do futuro são a matéria-prima para criação. Sem a consciência histórica, a criação não ocorreria, pois o sujeito haveria de estar sempre limitado ao agora que presentifica sua existência. Logo, a consciência histórica crítica não é de forma alguma provocada mediante uma narração eufórica de anedotas sobre o passado, sobre as 
curiosidades de grandes costureiros ou de marcas famosas e, menos ainda, de olhares superficiais sobre as épocas, sociedades e sujeitos sociais que nelas viveram. Uma consciência histórica crítica é peça chave para o desenvolvimento da criatividade, uma vez que, por meio dela, se alcança um pensamento autônomo, nada subserviente e, portanto, apto a desafiar problemas e ultrapassar fronteiras.

O ensino de História tem uma potência em propulsionar a criatividade tanto quanto os experimentos no campo do fazer em moda, porém, para tal, é preciso saber planejar e exercer a docência em história.

\section{PLANEJAMENTO: ENSINAR COM QUALIDADE}

Segundo Haydt (2006), planejar é analisar certa realidade, refletir sobre condições existentes, é prever formas alternativas de ação para sobrepujar dificuldades e alcançar objetivos almejados. Logo, o planejamento é um processo mental, envolvendo análise, reflexão e previsão. O planejamento de ensino é previsão das ações e metodologias que o professor vai realizar com seus estudantes, e a organização das atividades discentes de experiências de aprendizagem, dirigidas para que os objetivos estabelecidos sejam atingidos. Para tanto, as metodologias de ensino devem ser planejadas pelo professor, a fim de colocar o estudante em contato com os conhecimentos delimitados no propósito de adquirir habilidades previstas pelos objetivos.

As metodologias educacionais devem, portanto, contribuir para a mobilização dos esquemas operatórios de pensamento (estruturas conceptuais marcadas pela reversibilidade mental, esquemas que alimentam as estruturas lógicas e que alimentam os instrumentos cognitivos) e participação ativa do estudante nas experiências de aprendizagem, seja observando, lendo, escrevendo, experimentando, etc.

De acordo com Baggio, Schossler, Dullius (2010), o planejamento é necessário, como meio para facilitar e dinamizar o trabalho pedagógico. É um momento de reflexão sobre a ação, para pensar e melhor agir. Nesse processo deve ser considerada a realidade concreta e o que nela queremos mudar para melhor. Felis (2010) coloca o planejar como atividade dentro da educação, pois evita a improvisação, prevê o futuro, estabelece rotas que norteiam as execuções para as ações educativas. Planejamento e avaliação andam de mãos dadas. 
No processo de planejamento educativo, o instrumento maior é o Projeto Pedagógico do Curso (P.P.C.) no qual as diretrizes, objetivos e o perfil profissional do egresso, quando se trata de um projeto do ensino superior, constam para ordenar os demais planos de ensino que serão feitos para as diferentes disciplinas e que não deverão destoar, nos princípios ou conteúdos, do que se encontra proposto no P.P.C.

Para o ensino superior, o plano de aula é algo quase inexistente, pois não há cobrança administrativa do mesmo e nem os professores sentem a necessidade do planejamento detalhado dos minutos semanais passados juntos aos estudantes. Contudo, o plano de aula é um guia com função de orientar a prática didática em sala, é a formalização dos diferentes momentos do processo de ensinar, segundo Haydt (2006).

Por sua vez, Moretto (2007, p. 10) acredita que alguns componentes fundamentais devem ser considerados na elaboração do plano de ensino: conhecer sua própria personalidade enquanto professor, conhecer seus estudantes e suas características psicossociais e cognitivas, bem como ser o profissional adequado à disciplina em questão. As aplicações e escolhas dos métodos e técnicas devem depender dos objetivos estabelecidos. Por isso, as metodologias se adéquam aos seguintes fatores: objetivos estabelecidos, como já ditos; natureza do conteúdo a ser lecionado e tipo de aprendizagem a efetivar-se; as condições físicas e tempo disponível. Tais conhecimentos facilitam a escolha de metodologias de ensino mais adequadas e levam a resultados mais promissores. De acordo com Leal (2005), metodologia de ensino é o caminho utilizado para organizar as situações de ensino e aprendizagem. O conjunto de métodos e técnicas aplicados é justificado somente se objetivam promover a aprendizagem, ou seja, a metodologia de ensino escolhida pelo professor deve organizar as situações ensino e aprendizagem, de maneira propícia para a comunicação e entendimento dos saberes em questão.

O procedimento didático mais adequado à aprendizagem de determinado conteúdo é aquele que ajuda o estudante a incorporar novos conhecimentos de maneira ativa, compreensiva e construtivamente, de forma que estimule seu pensamento operatório, de acordo com Piaget, em sua obra Psicologia e Pedagogia (1970). Assim sendo, a função do professor é coordenar e facilitar o processo de reconstrução de conhecimento por parte do estudante, pois nem os conteúdos e objetivos são unos, e nem os sujeitos do processo são homogêneos. 
Todavia, para que o planejamento das disciplinas universitárias tenha o grau de excelência esperado, em que todos os esforços pedagógicos colimam no alcance geral do objetivo e perfil do egresso previsto no Plano Pedagógico do Curso, algo fundamental precisa ser garantido: de um lado, o conhecimento e preparação para o exercício da docência e, de outro, o conhecimento aprofundado da área de conhecimento em que o professor atua.

Infelizmente, na pesquisa realizada, nenhum dos dois fatores é realidade da maioria dos profissionais do ensino superior. Em poucos casos, o professor de disciplinas teóricas nos cursos pesquisados tinha uma formação específica na área de conhecimento e, também, possuía licenciatura na base da sua formação. Ao contrário, a maioria dos professores das disciplinas de História oferecidas nos cursos superiores pesquisados provém de bacharelados em áreas técnicas, como a Moda e o Design ou outros cursos distantes da pedagogia e da história.

Mais adiante se voltará às discussões sobre a formação dos professores, porém, em seguida, a fim de aprofundar reflexões específicas sobre as metodologias de ensino, dados quantitativos da realidade pesquisada serão analisados.

\subsection{METODOLOGIAS DE ENSINO: USOS E LIMITES}

A educação superior no Brasil, como aponta Paixão (2010), teve diferentes momentos, denominados fases, que se distinguem por características sociais, políticas e culturais específicas a cada época, resultando em processos de expansão e estagnação na educação do país. Assim, as décadas de 1960 e 1970 podem ser apontadas como primeiras fases da grande expansão da educação superior brasileira, vindas de um processo de implantação do capitalismo e da pressão de grupos sociais participantes desse processo.

Já, nos anos 1980, podemos observar uma estagnação, marcada por uma instabilidade e fragilidade do quadro educacional, seguidos pela década de 1990, onde contextos nacionais e internacionais impulsionaram uma reestruturação produtiva do capitalismo, sendo o conhecimento parte fundamental da produção e do acúmulo de vantagens diferenciais no cenário de competição global, o que gerou uma fase mais recente da expansão da educação, a chamada "universidade operacional”, de acordo com Caldas (2004), caracterizada pela ênfase na educação 
tecnológica de nível superior, obstinada na transmissão rápida de conhecimentos e treinamento sistematizado, a fim de vencer a demanda do mercado de trabalho.

Tal modelo universitário é largamente aplicado nos cursos de moda, tanto de tecnologia, quanto bacharelado. Assim sendo, o simples repasse de informação acaba sendo o objetivo traçado, especialmente para disciplinas teóricas, como a História.

Dentro de uma proposta pedagógica firmada na preparação rápida de mão de obra especializada para o mercado, nada mais natural do que a aula expositiva dialogada ser a metodologia mais utilizada no ensino, presente em $100 \%$ dos planos analisados durante a pesquisa.

A aula expositiva tem uma longa tradição: é, independente da área de conhecimento, uma das técnicas de ensino mais utilizadas pelos docentes universitários. De acordo com Godoy (2008), é mais voltada à transmissão de conhecimentos, busca basicamente a aquisição e compreensão de novos conhecimentos pelos estudantes, sendo, pois, frequentemente criticada por favorecer situações onde a aprendizagem é reprodutiva, já que o conteúdo que deve ser aprendido é apresentado aos aprendizes em sua forma final.

De acordo com Haydt (2006), a aula expositiva pode ser tanto dogmática, onde a mensagem transmitida não é contestada; quanto aberta e dialogada, onde há participação da classe, contestação, pesquisa e discussão. Atualmente, a expositivadialogada se difunde num sentido aberto, porém a aprendizagem significativa só acontece quando o estudante relaciona o novo conhecimento com anteriores, criando novas relações.

No ensino de História, tradicionalmente, a aula expositiva dogmática é largamente utilizada, quando não se tem entendimento de que a História não diz respeito apenas a momentos passados, fechados, sem possibilidades de interpretação e mudança. $O$ ensino da História exige pensamento crítico e julgamento, para que o tempo e a sociedade atual sejam compreendidos e, consequentemente, seu ensino possa basear-se apenas na discussão constante. Assim, a aula expositiva, se não aliada a desafios de raciocínio e interpretação, priva os estudantes de exercitar habilidades intelectuais mais complexas, tais como a aplicação, a análise, a síntese e o julgamento de dados, conjunturas e discursos necessários para o desenvolvimento do pensamento histórico-crítico. 
Por ser a técnica mais antiga e difundida de ensino, na educação de nível superior, muitas vezes, as alternativas a esta técnica, como por exemplo, o ensino em grupo e as propostas individualizadas de pesquisa e debate, têm sido mais usados para complementá-la do que para substituí-la. Dentre os 27 cursos de Moda em Santa Catarina e Rio Grande do Sul, existem 70 disciplinas cuja denominação contempla a nomenclatura História. Durante a coleta junto às instituições e professores, foi possível conseguir 42 planos de ensino das disciplinas ofertadas, o que correspondeu a $60 \%$ do total. Após, com o processo de análise realizado de cada quesito dos planos de ensino, chegou-se ao seguinte quadro em relação às técnicas de ensino:

Quadro 1: Técnicas de ensino utilizadas em sala, conforme nomenclatura encontrada no plano de ensino.

\begin{tabular}{|l|l|}
\hline Técnica & Santa \\
\hline Aula Expositiva & \\
\hline Debates & \\
\hline Leituras & \\
\hline Seminários \\
\hline Pesquisa \\
\hline Trabalhos \\
\hline Dinâmicas de grupo \\
\hline Análises \\
\hline Exercícios em sala \\
\hline Produção estudantes \\
\hline Estudo dirigido \\
\hline Estudos de caso \\
\hline Visita técnica \\
\hline Criação de roupas de papel \\
\hline Criação de vídeos \\
\hline Criação de croquis \\
\hline Criação de sketch book \\
\hline Portfólio \\
\hline Não consta técnica no plano \\
\hline
\end{tabular}

\begin{tabular}{|l|l|}
\hline Catarina & Rio Grande \\
\hline 26 & \\
\hline 17 & \\
\hline 9 & \\
\hline 6 & \\
\hline 1 & \\
\hline 3 & \\
\hline 2 & \\
\hline 1 & \\
\hline 3 & \\
\hline 3 & \\
\hline 1 & \\
\hline 1 & \\
\hline 1 & \\
\hline 1 & \\
\hline 1 & \\
\hline 1 & \\
\hline
\end{tabular}

\begin{tabular}{|c|c|}
\hline 10 & Total do Sul \\
\hline & 36
\end{tabular}

\begin{tabular}{l|l}
7 & 24
\end{tabular}

$6 \quad 15$

$5 \quad 11$

38

$6 \quad 7$

$2 \quad 5$

$3 \quad 5$

23

$0 \quad 3$

$0 \quad 3$

12

02

$0 \quad 1$

$0 \quad 1$

$0+1$

$0 \quad 1$

$1 \quad 1$

56

Fonte: Resultados da pesquisa de campo.

Como observado acima, depois da aula expositiva, encontram-se os debates, leituras, seminários, pesquisa e trabalhos num decrescer que aponta para um ensino centrado na figura do professor que expõe, enquanto os estudantes, por vezes, participam com suas opiniões, algumas vezes com pesquisas, leituras e trabalhos que ele próprio realiza. A baixa presença de dinâmicas de grupo, estudo dirigido e estudo de caso indicam aulas pouco instigantes e movimentadas. Os 
últimos itens evidenciam, com recorrência de apenas um caso por plano de ensino, técnicas próximas a outras disciplinas, talvez a trabalhos interdisciplinares, mas todos muito comuns num curso de moda.

Técnicas de ensino firmadas em propostas grupais, tais como debates, estudos dirigidos, seminários, dinâmicas de estudo e trabalho mediadas por diferentes audiovisuais, como filmes, documentários, entrevistas e etc., se bem desenvolvidas, são eficientes na promoção do interesse dos estudantes, na motivação deles para a pesquisa autônoma e solução de questões problemas que conduzem as técnicas de ensino acima enumeradas.

Em termos didáticos, os principais objetivos do trabalho em grupo são a facilitação da construção do conhecimento; a troca de ideias e opiniões; a possibilidade da prática da cooperação, visando a um fim comum. Além de contribuir para o desenvolvimento de esquemas cognitivos, o trabalho em equipe também favorece o convívio social, o planejamento em conjunto, divisão de tarefas e atribuições, aceitação de críticas construtivas, o respeito à opinião alheia, entre outras coisas. Porém, no quadro acima, é notável sua pequena utilização no ensino de História na Moda. Tal fato é preocupante, uma vez que o trabalho em equipe sempre propicia a discussão, exige a tomada de posição e decisões que afetam todo o grupo, amadurecendo a capacidade crítica diante dos temas de debate.

Além disso, há aspectos de relacionamento interpessoal bastante importantes a considerar. Desenvolver espírito de equipe não apenas facilita a construção de conhecimento, como também ajuda o estudante a desenvolver maior aceitação para troca de ideias, opiniões e críticas, possibilita a criação de senso colaborativo, buscando um fim comum: o ato de planejar de forma social e não individual, além de desenvolver respeito pela decisão da maioria. Tais fatores são importantes na formação profissional de um estudante de moda, pois são habilidades diferenciadoras num mercado de trabalho onde todo o processo de construção se dá em grupo, preparando-o melhor para ingressar no mercado de trabalho.

No universo de análise, portanto, notam-se dezoito variedades de metodologias aplicadas ao ensino de conteúdos de história. É possível também inferir que, numa mesma disciplina, são aplicadas mais de uma técnica de ensino por conteúdo, o que gera tecnicamente enriquecimento do processo de ensino e aprendizagem. 
A metodologia de ensino ou estratégia é, formalmente, dividida em técnicas de ensino e recursos didáticos. Completando as técnicas de ensino, um plano de ensino ideal deve discriminar os recursos de ensino. Os recursos didáticos são ferramentas de auxílio ao método utilizado, facilitando o aprendizado, tanto para o docente quanto para o estudante. Tem por função, entre outras, permitir o acompanhamento da argumentação apresentada, a retenção da atenção e, por fim, a compreensão dos conteúdos. Por isso, os recursos didáticos devem ser aliados e não complementos da exposição, criando situações onde haja participação e pensamento crítico, indo além da pura aceitação do conhecimento passado e reprodução do mesmo, sem questionamentos e interpretações particulares.

Materiais audiovisuais e equipamentos de multimídia são os recursos didáticos mais utilizados, junto com textos reproduzidos para leitura. Geralmente, são empregados como auxílio ao que está sendo exposto. Dentre eles, o uso de quadro negro ou seu similar tecnológico serve de apoio para a aula expositiva, assim como, os slides organizados em power point. Tais recursos didáticos não necessariamente fazem com que haja raciocínio, interpretação e transformação dos conteúdos por parte do estudante. Todavia, também não se pode afirmar que o cenário da interrogação, da crítica e da reflexão criativa não se imponha nas experiências de ensino e aprendizagem com a presença de recursos audiovisuais ou outros, já que isso depende, em larga medida, das formas de relação estabelecidas entre professor e estudante, conforme Haydt (2006) pondera com prudência.

O quadro abaixo demonstra quais técnicas e recursos são utilizados e sua frequência no universo de análise composto:

Quadro 2: Frequência de técnicas e recursos de ensino, por estado

\begin{tabular}{|l|c|c|c|c|}
\hline Estado & Técnica apresentada & Repetição & Recurso relacionado & Classificação \\
\hline SC & Expositiva Dialogada & 20 & Audiovisuais & 1 \\
\hline \multirow{4}{*}{ Debates } & 13 & Livros, Audiovisuais & 2 \\
\cline { 2 - 5 } & Leituras & 06 & Livros & 3 \\
\hline & Trabalho em Grupo & 06 & Livros, Audiovisuais & 4 \\
\hline & Análises & 04 & Livros, Audiovisuais & 5 \\
\hline & Estudos Dirigidos & 03 & & 6 \\
\hline & Seminários & 03 & Livros, Audiovisuais & 7 \\
\hline & Ex. de Criação & 04 & & 8 \\
\hline Pesquisa Bibliográfica & 02 & Livros & 9 \\
\hline & Outros & 01 & & 10 \\
\hline
\end{tabular}




\begin{tabular}{|c|c|l|r|}
\hline Trabalho em Grupo & 06 & Livros, Audiovisuais & 3 \\
\hline Leituras & 05 & Livros & 4 \\
\hline Análises & 04 & Livros, Audiovisuais & 5 \\
\hline Estudos Dirigidos & 03 & & 6 \\
Seminários & 05 & Livros, Audiovisuais & 7 \\
\hline Pesquisa Bibliográfica & 02 & Livros & 8 \\
\hline Exercícios em Sala & 02 & & 9 \\
\hline Outros & 01 & & 10
\end{tabular}

Fonte: Resultados da pesquisa de campo, 2012

Muitas vezes os recursos não são claramente descritos ou se mostram de forma truncada nos planos de ensino, criando dificuldades de associá-lo corretamente à técnica de ensino que completou. Outras vezes, a metodologia de ensino é muito ampla, abarcando diversos recursos. Na tabela acima, fez-se a citação literal dos termos obtidos nos planos de ensino e não se encontrou meios de considerar em que medidas os recursos citados se associaram a essa ou aquela técnica de ensino mencionada.

Segundo Masetto (2007, p. 11), novas metodologias desenvolvem a curiosidade dos estudantes, os instigando a buscarem novas informações. Diferentes técnicas de ensino, quando adequadas para se conseguir determinados objetivos, eficientes no contexto em que serão utilizadas e aplicadas por professores com domínio sobre sua execução, trazem importante contribuição para a aprendizagem.

Tal preocupação é de suma importância, pois, de acordo com Leal (2005), quando o professor escolhe um método ou técnica, pode privilegiar alguns estudantes, enquanto exclui outros. A exacerbação de um método pode impedir singulares experiências didáticas que o ajudariam a aperfeiçoar sua prática docente e possibilitariam diversas formas de aprender aos seus estudantes. Percorrer trajetos criativos em sala de aula, utilizando várias metodologias que se completem, enriquece o ensino e a aprendizagem, possibilitando maior crescimento, tanto do professor quanto dos estudantes.

Também, ainda cabe considerar nesta discussão que existem limitações como a pouca participação do estudante, a pouca leitura e a apatia diante de um ensino mais crítico. Geralmente, o ensino desprovido de criticidade é desenvolvido por anos a fio em escolas de ensino fundamental e médio castradoras (Ver OSTETTO, 2011). Por outro lado, o fato de professores considerarem a classe 
como um grupo uniforme, desconsiderando suas peculiaridades e interesses ou mesmo a falta de conhecimentos prévios e específicos do conteúdo do profissional ou de parte dos discentes, não favorece o entrosamento entre as partes envolvidas. Sem esses quesitos postos de antemão no fazer docente, o desenvolvimento de habilidades intelectuais mais complexas fica frustrado e aí se chega ao paradoxo infeliz do "eu faço que ensino e você faz que aprende".

Para o ensino de História acontecer de forma satisfatória, é necessário estimular o exercício de pensar crítico, envolvendo o pensamento criativo, desafiador e jamais apresentado pronto (DULCI, 2016).

Além dos recursos didáticos aplicados pelos professores, vistos no quadro anterior, alguma inovação temática no conteúdo aplicado pode estimular o exercício desse pensar crítico na História, habilitando os futuros designers a utilizar tal ferramenta em suas criações. Por outro aspecto, é necessário ponderar a qual objetivo geral a aula está subordinada e, dessa forma, escolher a mais adequada metodologia, para processar o ensino e aprendizagem almejados.

\subsection{OBJETIVOS E METODOLOGIAS DE ENSINO: DIÁLOGOS OBRIGATÓRIOS}

De acordo com Takahashi, Fernandes, (2004) cada aula apresenta uma situação didática específica e singular. Objetivos e conteúdo são desenvolvidos com métodos e modos de realização adequados, a fim de proporcionarem aos estudantes conhecimentos e habilidades, expressos por meio de uma metodologia compatível com a temática estudada. As técnicas e métodos devem ser pautados no processo didático e ter vínculo com a temática abordada, conteúdo específico e com os objetivos que devem ser alcançados. A metodologia é apenas o caminho que deve levar à concretização dos objetivos que os estudantes devem alcançar com os conhecimentos aplicados na disciplina. Sendo assim, objetivos e metodologia são via de mão única e devem coexistir, sem separação, uma vez que um deve ser pensado levando em consideração o outro.

O objetivo de um plano de ensino engloba as aptidões que o estudante deve desenvolver ao aprender os conteúdos conglomerados pela disciplina. Logo, deve haver um planejamento de quais metodologias e recursos deverão ser aplicados para que tais aptidões sejam desenvolvidas. 
Para SANT'ANNA (1993), os objetivos de um plano de ensino são sempre em longo prazo, porém cada aula apresenta também objetivos mais próximos que devem ser atingidos. Assim, cada aula e sua metodologia planejada é um importante passo para atingir o objetivo final. "Cada nova aprendizagem requer a existência dos elementos que constituem o ponto de partida, pois o que o aluno já sabe é crucial, uma vez que a aprendizagem é um processo cumulativo" (SANT'ANNA, 1993. p 31) e, assim, todos os demais itens do plano de ensino devem ser planejados, levando em consideração os objetivos e englobando os conhecimentos prévios dos estudantes.

Com base nas análises dos planos, constatou-se que os verbos de objetivos mais recorrentes são "desenvolver", "analisar" e "relacionar". Tal fato justifica a grande relevância das aulas expositivas dialogadas presentes nos planos, metodologia mais apropriada para disciplinas que objetivam "desenvolver" determinadas capacidades em seus estudantes, de acordo com o preceito que, a partir da exposição, o estudante irá assimilar e desenvolver novos conhecimentos. Tal fato também se aplica ao verbo "relacionar", vez que a exposição unida a audiovisuais (recurso mais recorrente nos planos) leva o estudante a exercer amplamente tal objetivo.

Leituras, pesquisas bibliográficas e seminários são metodologias que desenvolvem a capacidade de análise no estudante. Tal metodologia se encontra diretamente relacionada com o objetivo que almeja capacitar o estudante a "analisar".

As rápidas conclusões acima se baseiam na relação entre o que o objetivo quer capacitar no estudante e qual metodologia melhor supriria tal capacitação, se corretamente aplicada pelo professor.

Por exemplo, um plano de ensino, cujo objetivo geral é "Desenvolver nos estudantes o pensamento crítico a respeito do fenômeno da moda, compreendendo seus mecanismos de funcionamento, bem como sua evolução na sociedade atual"2, apresenta metodologias que englobam "aulas expositivas dialogadas, discussão circular, atividades em grupo, seminários e outras dinâmicas, leituras e pesquisas". A exposição dialogada, planejada pelo professor, seria para criar embasamento teórico e compreensão dos mecanismos de funcionamento do fenômeno moda e da sua

\footnotetext{
2 Plano de ensino da disciplina de História da Moda Contemporânea, ofertada na $3^{3}$ fase da Instituição 04 de S.C.
} 
evolução na sociedade atual. Tal ação criaria tanto um ambiente propício, quanto introduziria os conceitos aos estudantes, para que se fizessem discussões, atividades em grupo e seminários que complementariam a compreensão do estudante, assim como desenvolveria seu pensamento crítico, ao se posicionar e apresentar suas conclusões em tais dinâmicas. Por fim, as leituras e pesquisas complementariam a interpretação, entendimento dos estudantes e senso crítico. De modo geral, o objetivo proposto caminha junto às metodologias descritas, proporcionando ao estudante meios de alcançar as qualificações almejadas pela disciplina.

Outro exemplo pertinente é um plano que apresenta como objetivo geral "Relacionar a história, o design, a moda e a arte através do olhar analítico, crítico e estético exigido aos futuros profissionais da Moda, compreendendo as mudanças sociais e as importantes contribuições da história para nosso presente" 3 e, neste mesmo plano de ensino, as metodologias citadas são: aulas expositivas dialogadas, leitura de textos e fichamento, pesquisas, participações em fóruns virtuais, produção de textos e croquis de moda. Ao fazer uso da aula expositiva dialogada, talvez, o professor tenha aberto caminhos para que as relações entre os diversos conteúdos se formassem a partir do pensamento do estudante, o que poderia ajudá-lo a compreender as mudanças sociais e contribuições da História para o presente. Tal método embasaria teoricamente 0 estudante, para que este fosse apto a desenvolver um olhar analítico, crítico e estético, por exemplo. Pesquisas, leituras e fichamentos também são ferramentas de auxílio para tal formação. As participações em fóruns virtuais devem desenvolver o senso crítico do estudante, se tal método for aplicado em um sentido de criar debates e discussões sobre os conteúdos abordados em sala. A produção textual, além de desenvolver a criticidade e compreensão do estudante, pode ajudá-lo a desenvolver as relações entre os diversos conteúdos e exercitar sua criatividade, bem como os exercícios de criação auxiliariam o estudante a colocar sua criatividade em prática, num suporte bastante dominado por ele.

Talvez coubesse, ainda, nessas metodologias, aplicar seminários e debates em sala, abrindo maior espaço para a discussão crítica e relações de diversos conteúdos por parte dos estudantes. Como não podemos saber como tais

\footnotetext{
${ }^{3}$ Plano de ensino da disciplina "História da Moda e do Design", ofertada na $2^{\mathrm{a}}$ fase da Instituição 02 de R.S. 
técnicas de ensino se aplicaram na prática, fica aberta tal lacuna em relação ao completo desenvolvimento da capacidade analítica, crítica e estética dos estudantes tal como o objetivo geral previa; não sabemos se tais habilidades se desenvolveram por completo no decorrer da disciplina ou o que se encontrava planejado não foi nem mesmo aplicado.

Apesar de haver certa carência no documento escrito a respeito tanto de metodologias quanto de objetivos, sabe-se que uma aula sempre vai além. Ainda que haja essa defasagem entre o escrito e o possivelmente praticado, as análises acima expõem de forma nítida que metodologias de ensino e objetivo se completam, buscando um fim comum: a habilitação de um estudante mediante determinados conteúdo.

É importante frisar que as metodologias devem ser planejadas, considerando tanto os objetivos quanto os conteúdos e devem ser bem aplicadas, para que se alcancem os objetivos propostos. Uma exposição onde não há espaço para o discente perguntar, criar novas referências, discutir e tirar conclusões por conta própria, por exemplo, não permite que objetivos como "desenvolver" e "relacionar" se concretizem.

É certo que o diferencial está em metodologias, recursos didáticos e avaliações que estimulem o estudante a ir além e buscar fontes, pesquisar e pensar historicamente, unindo isso a sua criatividade em amadurecimento, o que contribui para que a consciência histórica crítica esteja sempre em crescimento e em uso. Tais atividades ajudam o estudante a perceber que a História da Moda vai além da informação e está presente também na prática, sendo peça fundamental para a formação e trabalho interdisciplinar. Porém, a proposta do ensino deve seguir muito além da composição de um repertório rico e variado.

O dever do ensino de História se atrela ao estímulo crítico de pensar a sociedade e os sujeitos sociais em suas relações cotidianas, marcadas por inúmeros fatores e os muitos que não são, de forma alguma, cotejados apenas pelo olhar inexperiente de quem observa o resultado. Pensar historicamente é encadear o fazer do aqui e agora numa grande historicidade, que de forma alguma é a manifestação do progresso da humanidade, como os idealistas alemães defendiam no século XIX. É, sobretudo, compreender que as maneiras de pensar e fazer dos sujeitos de hoje implica maneiras de narrar e produzir sentidos para a vida e as coisas que a compõem: o chamado passado. 


\section{A FORMAÇÃO DOS PROFESSORES ATUANTES NAS DISCIPLINAS DE HISTÓRIA}

Por maiores que sejam as excelências que os profissionais tragam de suas áreas de atuação, não há garantias de que as mesmas exercerão igual peso na construção dos significados, saberes e competências, compromissos e habilidades alusivos à docência. O fato de professores universitários não possuírem qualquer formação pedagógica é uma regra, mesmo que medidas legais tenham incorporado como exigência nos cursos de pós-graduação latu sensu disciplinas vinculadas à docência do ensino superior. $\mathrm{Na}$ atualidade, os professores universitários, a maioria doutores ou mestres, ingressaram no exercício do magistério sem ter cursado as disciplinas didático-pedagógicas em sua formação de pós-graduação e, quase sempre, são excelentes pesquisadores e nem sempre tão bons professores.

Essa situação é recorrente no ensino da moda, pois, como aponta Caldas (2004), o ensino superior de moda no Brasil é relativamente novo e, em função disso, os professores que assumem as disciplinas são oriundos das primeiras turmas graduadas em Moda ou de outras áreas, não necessariamente ligadas à moda, não possuindo preparação para a docência. Engenheiros, arquitetos, economistas, designers e outros tantos cursos superiores sem nenhuma relação com o universo da educação compõem a origem de formação da maioria dos professores atuantes nos bacharelados e tecnólogos em Moda.

Agravante a essa situação, muitas vezes não há incentivo por parte institucional ou interesse do docente para que uma especialização voltada para o magistério seja realizada. Em geral, os professores de ensino superior consideram a pedagogia desnecessária às suas reflexões e mesmo os núcleos docentes estruturantes servem mais para regular as questões administrativas do ensino, ao invés de refletir sobre as práticas pedagógicas, numa atitude de permanente autoavaliação.

Mas, indo além de conjecturas, dados coletados apontam quais as formações que os professores das disciplinas História da Moda possuíam, no começo da década atual, nos estados de Rio Grande do Sul e Santa Catarina.

Em um primeiro momento, através de pesquisas no site do Ministério da Educação, constatou-se que existiam 27 instituições que ofereciam cursos de Design de Moda, tanto técnicos quanto bacharelados, em 2012, sendo 18 em Santa 
Catarina e 9 no Rio Grande do Sul. Após a identificação desses cursos, entrou-se em contato com as instituições, através do sítio eletrônico, e-mails e telefonemas, a fim de descobrir quais as disciplinas com o termo "história" eram oferecidas pelos cursos, e quais os professores responsáveis por elas no ano anterior. Obteve-se relativo êxito nessa fase da pesquisa, conseguindo a relação de todas as disciplinas de história nos cursos de Design de Moda tanto em Santa Catarina quanto no Rio Grande do Sul e a relação dos professores atuantes de 8 cursos do Rio Grande do Sul e dos atuantes em 15 cursos de Santa Catarina. Depois disso, os nomes coletados foram consultados na base pública de currículos do CNPq (Conselho Nacional de Desenvolvimento Científico e Tecnológico) para verificação da formação dos profissionais atuantes em 2011. Após todas as etapas de coleta e verificação, os dados foram tabulados em gráficos, para análise.

No Rio Grande do Sul, observou-se que nenhum professor atuante em disciplinas com o termo "história" tinha apenas graduação; 16\% tinham especialização; enquanto 53\% eram portadores do título de mestre e $31 \%$ de doutor. O fato de todos terem ao menos uma pós-graduação é ponto positivo e talvez, hoje, em 2018, não haja mais um percentual expressivo de especialistas, o que demonstra preocupação constante com a formação profissional por parte dos professores, fato que contribui muito para a docência, já que, de acordo com Silva e Reis (2011), requer constante formação do profissional.

Em Santa Catarina existia maior equiparidade em relação às titulações dos docentes, sendo $16 \%$ portadores apenas do diploma de graduação; 16,29\% com especialização; 34\% com mestrado e 21\% com doutorado. Mesmo que houvesse professores apenas com graduação, a quantidade de doutores e mestres era expressiva.

Além da titulação usufruída à época da pesquisa, considerou-se que áreas de formação principal os profissionais possuíam, pois apenas a titulação de doutor, por exemplo, não garantiria um aprofundamento em questões de didática e docência. Os gráficos abaixo nos trazem a relação da área de titulação desses profissionais, tanto em SC quanto no RS, considerando apenas a graduação, entendida como a mais importante na definição do perfil formativo do profissional. 
Gráfico 1: Distribuição dos professores por área de graduação, atuantes em SC.

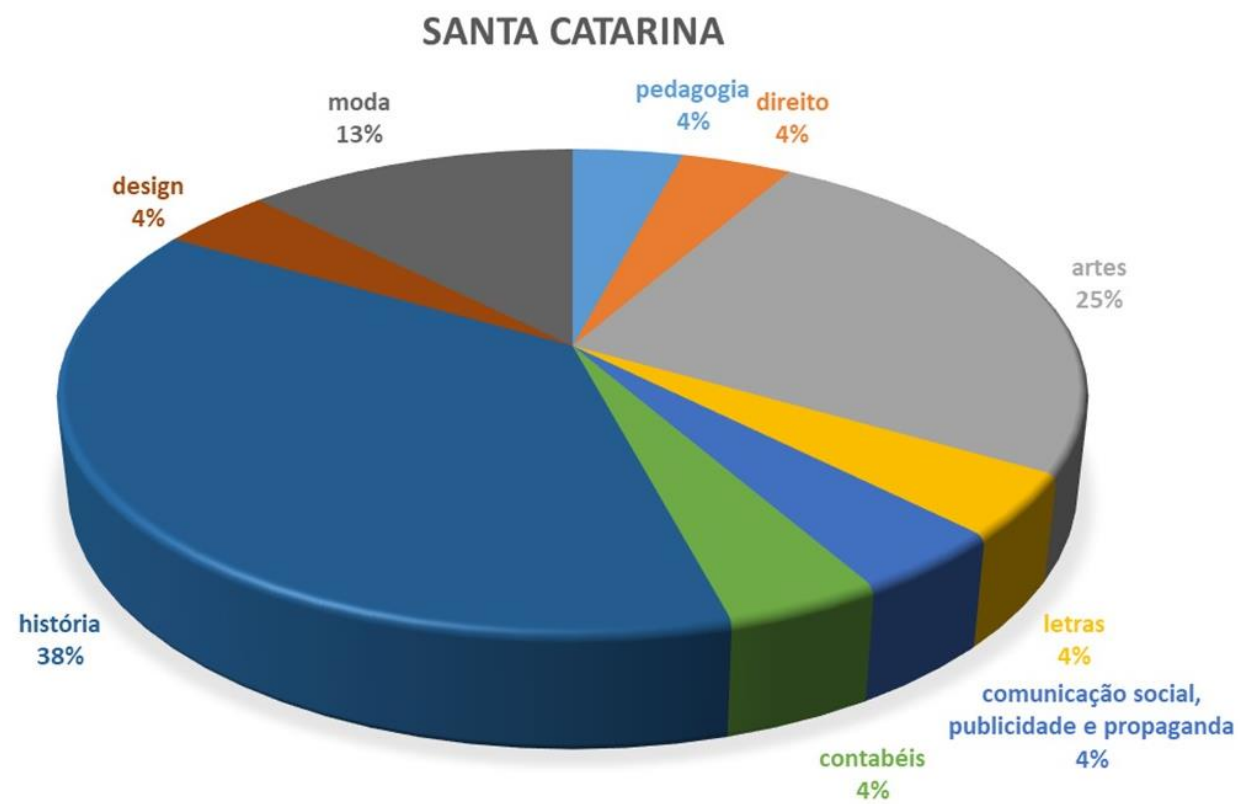

Fonte: Resultados da pesquisa de campo, 2011.

Gráfico 2: Distribuição dos professores por área de graduação atuantes em RS

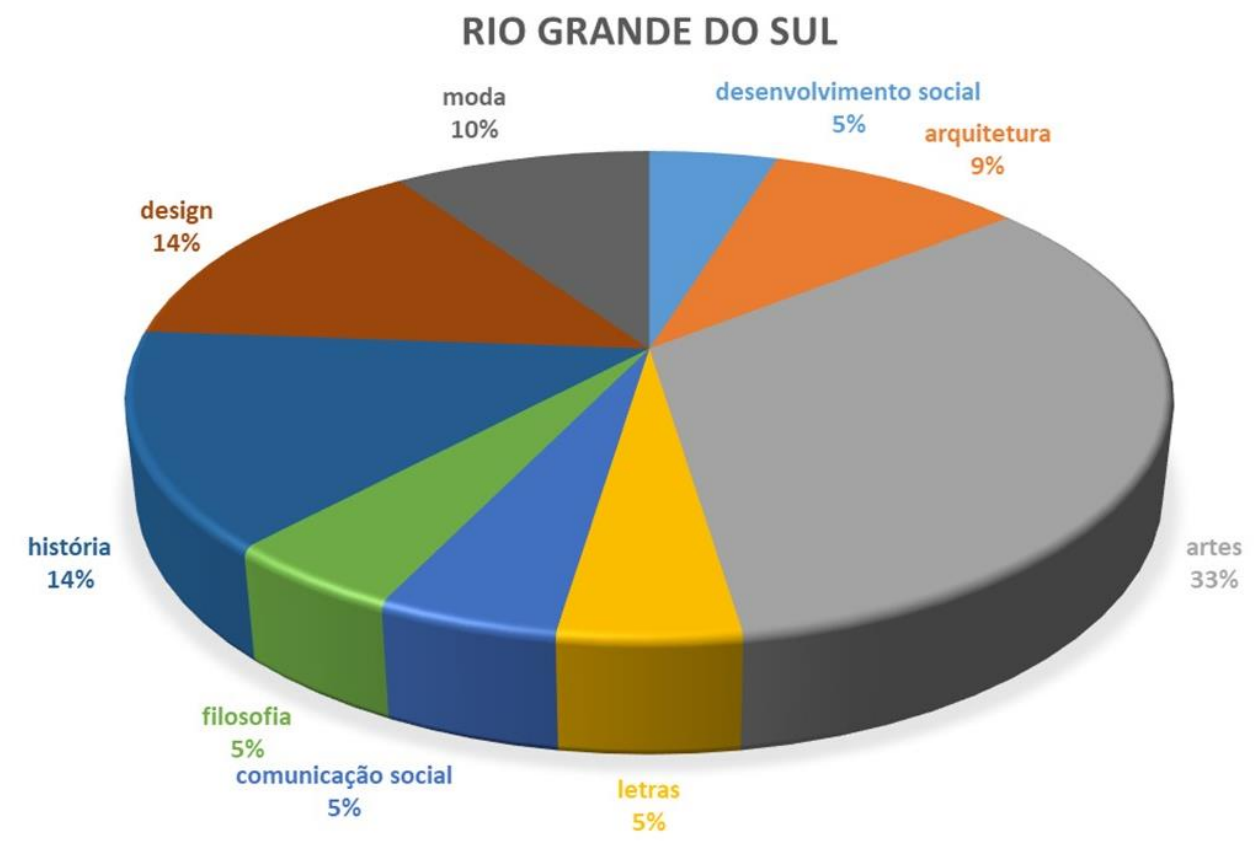

Fonte: Resultados da pesquisa de campo, 2011.

Observa-se, positivamente, nos dois gráficos, que um número considerável de profissionais possuía titulação em História, assim como em outras áreas envolvidas com a docência, como Artes, Filosofia, Letras e Pedagogia que trabalham com a didática em seu plano curricular, caso seja um curso de 
Licenciatura. Contudo, essas últimas áreas de conhecimento não oferecem em sua formação um aprendizado aprofundado em História, sendo apenas a Filosofia a que mais se aproxima. O caso se agrava com a falta de aprofundamentos didáticos ou a completa ausência deles como na situação dos professores graduados em Moda, Design, Arquitetura, Comunicação, Direito, Contábeis e Desenvolvimento Social, cursos em que nada é ensinado no campo do ensino. Soma-se, a essa formação distante da pedagogia, ainda, o fato de as disciplinas de história serem diminutas nos currículos e, como está se estudando, quase sempre são disciplinas oferecidas por advogados, arquitetos, designers, contadores etc. e não por historiadores.

Considerando o número de profissionais com formação em História, temse: $38 \%$ de professores formados na área em SC e apenas 14\% no RS. Assim, em Santa Catarina, o maior índice do gráfico corresponde aos profissionais com formação em História. $E$ isso é relevante, uma vez que a Licenciatura em História traz disciplinas importantes para a docência. Usando como exemplo o curso de História da Universidade Federal de Santa Catarina ${ }^{4}$, das 31 disciplinas obrigatórias, seis são voltadas para a didática e ensino, uma para as metodologias, e existem três estágios onde o estudante é colocado em contato direto com o ensinar e orientado para fazê-lo com maestria. Além disso, toda disciplina, mesmo voltada para um conteúdo específico, como História Moderna, é discutida de maneira crítica, questionando a escrita desse passado, seus modelos ideológicos e suas apreensões no presente, apurando, assim, o estudante para se tornar um historiador e não um contador de fatos passados. Deve-se acrescentar que outras disciplinas optativas voltadas para a pedagogia são oferecidas pelo curso e existe um Laboratório de Ensino onde diversas atividades de ensino, pesquisa e extensão são produzidas, dando um amplo embasamento didático-pedagógico para os profissionais formados na instituição.

Assim, além de o profissional formado em história ter pleno domínio das construções dos conhecimentos historiográficos, das problematizações e do entendimento da consciência histórica, também tem uma base fomentadora do magistério, estando apto para aplicar sua maturidade historiográfica às disciplinas História da Moda com destreza. Algo bem diferente ocorre, por exemplo, com um graduado em Moda, cuja carga horária de disciplinas de história não ultrapassa 10\%

4 Conforme proposta pedagógica vigente em 2018. Currículo de 2007. Ver http://cagr.sistemas.ufsc.br/relatorios/curriculoCurso?curso=326. Acesso 23/03/2018 
da carga horária total do currículo, isso ainda nos melhores casos (SANT'ANNA, 2012).

No Rio Grande do Sul, entretanto, a realidade se mostra um pouco diferente. Um número relativamente pequeno dos professores ministrantes de disciplinas de História possui, de fato, alguma formação relacionada à história. Tal fator é preocupante, pois pode significar lacunas no ensino histórico, como a falta de problematizações, de entendimento da consciência histórica e da construção (e não mero repasse) dos saberes históricos. Como Susana Bernardo defende: "A aprendizagem histórica deve ser planejada, para contemplar múltiplas habilidades e competências, assim como o desenvolvimento de procedimentos que auxiliem na formação histórica" (BERNARDO, 2009, p. 43).

Assim, somente o profissional competente para a transmissão de conteúdos pode fornecer aos estudantes de História da Moda um ensino histórico completo, não apenas dos fatos, mas sim dos contextos, que ensine a pensar e questionar, e não somente fixar nomes de estilistas ou grifes de moda e ter uma noção do tempo e das crises sociais com simplificações ao estilo "Wikipédia". O profissional que ensina a História da Moda precisa estar deslocado da antiga ideia simplista de mera reprodução do conhecimento, para a construção e contextualização do conhecimento, a fim de produzir uma consciência crítica e autoral no estudante.

Como Silva e Reis discutem, quando o professor não possui êxito em ministrar o conteúdo de sua aula, "a tarefa de ensinar acaba por contribuir mais para o desencanto do estudante em relação à aprendizagem do que para o incentivo e produção do conhecimento" (SILVA; REIS, 2011, p. 2). Tal fato, unido ao número de professores sem formação ou especialização que contemple a didática, pode explicar um possível desinteresse dos estudantes pelas disciplinas de história dentro dos cursos de Moda.

Sem especializações voltadas para a disciplina a ser aplicada e para a docência, outro fator de desarranjo no ensino de História se impõe, uma vez que, na maioria das situações, quando um professor ingressa no curso/departamento encontra já estabelecida a disciplina em que atuará, recebendo ementas prontas e mesmo "diretrizes", como determinados tipos de trabalhos e livros a serem usados. Tal fato isola a disciplina do conjunto formativo a que o curso se propõe e gera uma situação onde o professor planeja individualmente e, de modo geral, os resultados 
que obtém não são estudados e analisados pelo conjunto docente, a não ser que apresentem situações conflitantes.

Junta-se, ainda, à formação precária e ao conhecimento raso, questões como: a inexistência de orientações quanto ao planejamento do ensino, o uso de metodologias ou das avaliações praticadas; falta, igualmente, a realização de estudos e discussões sobre as práticas docentes, de autoavaliações ou relatórios nas operações docentes de maneira sistemática e em busca da qualidade. De modo geral, no ensino superior, poucas são as ações que criem reflexão sobre a docência ou sobre o processo docente e a efetivação de um perfil profissional almejado. Sempre será escrito no PPC sobre o perfil do egresso, mas quantas serão as ocasiões que o corpo docente desacelera suas atividades para refletir se o perfil desejado está sendo produzido pelas ações educativas encetadas? Essas e outras questões geram ainda muitas polêmicas, porém não são abordadas nesse texto.

Importa, ao menos, destacar que muito se pode fazer com a quebra dos paradigmas que entornam o conhecimento de História, por muito tempo entendido como um saber firmado na narração de fatos e heróis, o que, supostamente, lendo um livro e pesquisando na internet, preparando slides com figuras bonitas já seria o suficiente para ensinar sobre o passado. Os profissionais convidados a lecionar História ou outras áreas específicas das Ciências Humanas sem contínuo aprofundamento, tanto da prática docente quanto em relação aos conteúdos específicos, jamais poderão despertar nos estudantes o entendimento crítico e fazêlos se tornarem agentes criativos de sua ação profissional.

E vai mais além a discussão. Supor que qualquer graduado em design, por exemplo, pode ser um professor de História, caso goste de ler, é reafirmar que, nos cursos de Moda, as disciplinas mais teóricas e de cunho histórico são consideradas informativas ao invés de formativas, ou seja, "complementares" ao curso e até dispensáveis. Mas, vamos parando por aqui.

\section{CONSIDERAÇÕES FINAIS}

Um ensino crítico e criativo alude à liberdade de exploração e do questionamento de teorias, informações e técnicas, sendo importante que todas as disciplinas proporcionem, num curso voltado à criação como o de Design de Moda, oportunidades de aprofundamento, de exposição, de descoberta e resolução de 
questões e problemas a partir de leituras e debates, de experimentações e de confrontos conceituais e de práticas.

Por isso, um ensino criativo vai além da reprodução de conhecimento, onde o estudante decora e reporta o conhecimento passado em sala em provas e trabalhos que não aprimoram a capacidade crítica do aprendiz. A demanda de trabalhos e exercícios, como croquis e outros relacionados à produção de vestimentas ou imagens, sem ser acompanhados da devida discussão e afastamento da reprodução do já visto, pouco ou nada acrescentam na tomada de uma consciência histórica crítica.

Todo estudante precisa de encorajamento do professor, para que aprenda a questionar, expor, problematizar e utilizar os conhecimentos apreendidos, incentivando um pensamento crítico e criativo, original e isso desde a mais tenra idade. O estudante universitário, que não se impõe o desafio de superar a rotina colegial e a relação autoritária entre professor que ensina e estudante que aprende, não se apropria da dimensão inovadora que a universidade deveria, por princípio, valorizar, viabilizar e centralizar em suas ações.

Todas as disciplinas deveriam ter isso em pauta no planejamento de suas ações educativas, tendo clareza de que não se trata de informar práticas, métodos e teorias, mas instigar o estudante, numa postura crítica a rever os conteúdos, técnicas e métodos com que toma contato, a fim de provocar inquietações internas no já sabido e, então, produzir novos conhecimentos para si e seu entorno.

Portanto, a partir das análises realizadas ao longo da pesquisa foi possível notar que, muitas vezes, como tantas outras disciplinas teóricas aplicadas em um curso prático por excelência, a História ensinada nos cursos superiores de Moda é categorizada nas grades curriculares e mesmo pelos futuros profissionais como informativa, e não formativa e, sendo assim, esquecida logo após a conclusão da disciplina ou reduzida em sua carga horária. Possivelmente, tal forma de pensar resulte das situações de mera reprodução do conhecimento histórico que ocorrem em aulas expositivas, acompanhadas de slides bonitos ou nem tanto, mas, que, infelizmente, não provocam qualquer envolvimento mais complexo das habilidades do raciocínio e crítica. Esta impossibilidade se dá porque a maioria dos professores não é habilitada (apenas $38 \%$ em SC e 14\% no RS), possui pequeno ou pontual entendimento da história e recebe estudantes acomodados a não discutirem o que Ihes é dito. 
Entrelaçar fatores sociais, econômicos, culturais e discursivos, pensar além da narração do acontecimento histórico, questionar os seus bastidores, por exemplo, requer pensamento crítico e ativo, por parte de quem está mediando o conhecimento já constituído e do ouvinte, especialmente, quando a disciplina é a História. Mesmo que os verbos "desenvolver', "analisar" e "relacionar" tenham sido os mais recorrentes nos planos de ensino e, quase sempre, havido a menção a metodologias capazes de alcançar os objetivos, não se pode afirmar que tais objetivos contribuíram para a formação de um Designer de Moda crítico e criativo. Todavia, nas disciplinas dirigidas por um historiador isto teve mais chances de ocorrer.

Fica claro que se faz necessária uma reflexão da importância do ensino de História e deve acontecer no duplo sentido docentes - discentes. Para tal, é mister formação de historiador para quem leciona esse conhecimento e contínua reflexão de seu fazer docente. Isto acompanhado de uma postura institucional de implementação de estratégias pedagógicas que incrementem a qualidade dos planejamentos de ensino, nos quais objetivos, conteúdos e metodologias de ensino cooperam-se mutuamente, para que a compreensão histórica e de todos os campos de conhecimento afeitos à formação do futuro designer de moda influenciem na postura crítica e, consequentemente, na criatividade do profissional em meio à sociedade em que atua.

Acredita-se que o objetivo proposto com o artigo foi alcançado, pois se discutiu a dimensão do ensino de História da moda nos cursos de Design de Moda, cotejando a importância do desenvolvimento da consciência histórica crítica dos estudantes em diferentes momentos do texto e, especialmente, quando foram analisadas as metodologias de ensino aplicadas e os objetivos gerais que as motivaram, bem como ao ponderar a formação e capacitação dos professores atuantes no ensino de História na época da pesquisa de campo. Na combinação desses aspectos, conclui-se, então, que a consciência histórica crítica não é desenvolvida a contento no ensino de História da Moda, principalmente, devido à ausência de historiadores ministrando essas disciplinas e não por conta das metodologias utilizadas ou dos objetivos propostos para as mesmas.

Deixa-se o convite para uma futura pesquisa aos nossos leitores, cuja proposta seria de comparar o resultado final dos cursos de graduação em Moda, por meio dos trabalhos de conclusão de curso entregues, com a carga horária, formação 
de professores e propostas de ensino das disciplinas teóricas existentes nas matrizes curriculares, a fim de averiguar se em currículos com maior relevância às disciplinas teóricas e devida formação dos professores responsáveis por elas, os TCC são mais consistentemente críticos à sociedade que os entorna e os problemas de pesquisa são tratados com maior inovação ou não.

Espera-se que a longa leitura tenha valido a pena; que esse texto tenha alimentado a autocrítica e provocado algumas inquietações nos pesquisadores e professores dos cursos de Design de Moda ou afins.

\section{REFERÊNCIAS}

ANASTASIOU, Lea das Graças C. Construindo a docência no ensino superior: relações entre saberes pedagógicos e saberes científicos. In: ROSA, Dalva E. Gonçalves; SOUZA, Camilo de Souza. Didática e práticas de Ensino: interfaces com diferentes saberes e lugares formativos. Rio de Janeiro: DP\&A, 2002.

BAGGIO, G., SCHOSSLER, D., DULLIUS, M. Utilizando diferentes metodologias para o ensino de matrizes: Uso de modelagem matemática e recursos computacionais em dois ambientes escolares. Revista dos Destaques Acadêmicos, ano 2, $\mathrm{n}$ 4, 2010, p. 9-15. Disponível em: http://www.univates.br/revistas/index.php/destaques/article/viewFile/104/62

BENJAMIN, Walter. Sobre o conceito de história. In: Obras Escolhidas, vol. 1. Org. Sergio Paulo Rouanet, SP: Brasiliense, 1987, pp. $222-232$.

BERNARDO, Susana Barbosa Ribeiro. O ensino de história nos primeiros anos do ensino fundamental: o uso de fontes. 2009. 159 f. Dissertação (Mestrado em História Social) - Centro de Letras e Ciências, Universidade Estadual de Londrina, Londrina. 2009.

BONADIO, Maria Claudia; MARINHO, Maria Gabriela S. M. C.; WAJNMAN, Solange. Moda e conhecimento: Interfaces com as ciências humanas e a comunicação. lara: Revista de Moda, Cultura e Arte, São Paulo, v. 3, n. 3, p.01-04, 12/2010. Disponível em: <http://www1.sp.senac.br/hotsites/blogs/revistaiara/wpcontent/uploads/2015/01/IARA _vol3_n3_Completa_2010.pdf\#page=53>. Acesso em: 19 set. 2016.

CABRAL, Maria Helena. História e Medicina: a Herança Arcaica de um Paradigma. Revista Eletrônica História, Ciências, Saúde, on-line. Rio de Janeiro, nov 1999 fev 2000, p. 551-575.

CALDAS, Dario. Cursos e Desvios do Ensino Superior de Moda. In: CALDAS, Dário. Observatório de Sinais: teoria e prática da pesquisa de tendências. Rio de Janeiro: Editora Senac Rio, 2004. 
CERRI, Luis Fernando. Ensino de História e consciência histórica: Implicações didáticas de uma discussão contemporânea. 1. ed. Rio de Janeiro: Editora FGV, 2011.

DULCI, Luciana Crivellari. O conhecimento nos cursos superiores brasileiros: a constituição da formação em Design de Moda. In: CONGRESO DE LA ASOCIACIÓN LATINOAMERICANA DE SOCIOLOGIA, 29., 2013, Chile. Acta Cientifica. Chile: Alas, $2013 . \quad$ p. $1121 . \quad$ Disponível em: <http://actacientifica.servicioit.cl/biblioteca/gt/GT25/GT25_CrivellariDulci.pdf>. Acesso em: 01 dez. 2016.

FELIS, C., P. Planejamento escolar. Disponível em: <http://recantodasletras.uol.com.br/artigos/33896>. Acesso em: 2010

FERREIRA, Terezinha Francelino. A Disciplina História da Matemática: um estudo sobre as concepções do professor do ensino superior. 2005. 146 f.. Dissertação (Mestrado em Matemática) - Pontifícia Universidade Católica, São Paulo, 2005.

GODOY, Arilda Schmidt. Revendo a aula expositiva. In: MOREIRA, Daniel Augusto (Org.). Didática do ensino superior: técnicas e tendências. São Paulo: Pioneira, 2000.

HAYDT, R. C. C. Curso de didática geral. 8. ed. São Paulo: Ática, 2006.

LEAL, R. B. Planejamento de Ensino, Peculiaridade significativas. Revista Iberoamericana de Educación, Vol. 37, n. 3, 2005. Disponível em: http://www.rieoei.org/deloslectores/1106Barros.pdf

LEITE, Sérgio Antônio da Silva. Desenvolvimento Profissional do Professor: Desafios institucionais. In: SADALLA, A. M. F. de; AZZI, R. G.; BATISTA, S. H. S. S. (Orgs). Formação de Professores: discutindo o ensino de Psicologia. $2^{\underline{a}}$ Ed. Ver. São Paulo: Alínea, 2016.

MASETTO, M. T. (Org) Ensino de engenharia: técnicas para otimização das aulas. São Paulo: Avercamp Editora, 2007.

MORETTO, V. C. Planejamento: Planejando a educação para o desenvolvimento de competências. Petrópolis: Vozes, 2007.

OKI, Maria da Conceição Marinho. MORADILLO, Edílson Fortuna. O ensino da História da Química: contribuindo para a compreensão da natureza da ciência. Revista Ciência e Educação, on-line, 2008, p. 67-88.

OSTETTO, Luciana Esmeralda. Educação infantil e arte: sentidos e práticas possíveis. Caderno de Formação: formação de professores educação infantil princípios e fundamentos. Acervo digital Unesp, v. 3, p. 27-39, mar. 2011. Disponível em: $\quad$ <https://acervodigital.unesp.br/bitstream/123456789/320/1/01d14t01.pdf> Acesso em: 19 mar. 2018. 
PAIXÃO, Cassiane de Freitas. Educação superior no Brasil: diferentes fases, outras características. Caderno ANPAE, on-line, 2010.

PROUST, Antoine. Doze lições sobre a história. Belo Horizonte: Autêntica Editora, 2008.

SADALLA, Ana Maria Falcão de Aragão. Teorias Implícitas na Ação Docente: Contribuição teórica ao desenvolvimento do professor prático-reflexivo. In: SADALLA, A. M. F. de; AZZI, R. G.; BATISTA, S. H. S. S. (Orgs). Formação de Professores: discutindo o ensino de Psicologia. 2a ${ }^{\underline{a}}$ Ed. Ver. São Paulo: Alínea, 2016.

SANT'ANNA, Ilza Martins. Didática - aprender a ensinar. Rio de Janeiro: Editora Loyola, 1993.

SANT'ANNA, Mara Rúbia. Disciplinas teóricas e a formação do profissional de moda - estudo a partir da História da Moda. In: International Fashion and Design Conference, 2012, Guimarães. Anais 1o. CIMODE. Porto: Universidade do Minho, 2012. v. 1. p. 3061-3072.

SILVA, Lívia Ramos de Souza, REIS, Marlene Barbosa de Freitas. Docente do ensino superior e a importância da formação pedagógica. In: Anais do I Seminário sobre docência universitária. Universidade Estadual de Goiás, março de 2011, pp. $1-30$.

TAKAHASHI. R. T., FERNANDES, M. F. P. Plano de aula: conceitos e metodologia. Revista ACTA, v. 17, $\mathrm{n}$ 1, 2004, p.114-118. Disponível em: <http://lms.ead1.com.br/upload/biblioteca/modulo_3658/QGFZJBHV7Z.pdf> Acesso em 12 de dezembro de 2014. 